\title{
Household air pollution and under-five mortality in India (1992-2006)
}

Sabrina Naz ${ }^{1 *}$, Andrew Page ${ }^{1}$ and Kingsley Emwinyore Agho $^{2}$

\begin{abstract}
Background: Household air pollution (HAP) - predominantly from cooking fuel is a major public health hazard and one of the leading causes of respiratory illness and deaths among children under-five years in India. This study investigates the association between HAP from cooking fuel and under-five mortality using India's National Family and Health Survey (NFHS) datasets over the period 1992-2006 (total of 166,382 children), and the extent to which the association differed by environmental and behavioral factors affecting level of exposure.

Methods: The association between HAP and under-five mortality of three age-groups (neonatal age between 0-28 days, post-neonatal age between 1-11 months and children aged between 12-59 months) was examined using multi-level logistic regression models.

Results: HAP was associated with mortality among children aged under-five $(\mathrm{OR}=1.30,95 \% \mathrm{Cl}=1.18-1.43, P<0.001)$ and was more strongly associated in sub-group analyses of post-neonatal mortality $(\mathrm{OR}=1.42,95 \% \mathrm{Cl}=1.19-1.71$, $P<0.001)$ and child mortality $(O R=1.42,95 \% \mathrm{Cl}=1.05-1.91, P=0.021)$ than neonatal mortality $(\mathrm{OR}=1.23,95 \% \mathrm{Cl}=$ 1.09-1.39, $P=0.001$ ). The association was stronger for households in rural areas and for households without a separate kitchen using polluting fuel, and in women who had never breastfed for all age-groups.

Conclusion: Use of cooking fuel in the household is associated with increased risk of mortality in children aged under-five years. Factors relating to access to clean fuels, improvements in infrastructure and household design and behavioral factors are discussed, and can result in further declines in under-five mortality in India.
\end{abstract}

Keywords: Household air pollution, Under-five mortality, Child mortality, Cooking fuel, India

\section{Background}

India is the second most populous and seventh largest country by area in the world located in South Asia, and currently is one of the ten fastest growing economies in the world [1]. In the last five decades in India, there has been extensive improvement in poverty reduction, literacy, health standards and human development, however, there remains significant population challenges in relating to health and sanitation [1]. More than $90 \%$ of the rural population and $31 \%$ of the urban population in India still rely primarily on solid fuels as a domestic source of energy [1-3]. Household air pollution (HAP) from solid fuels (such as wood, animal dung, crop residues, charcoal and

\footnotetext{
*Correspondence: sabrinanaz@gmail.com; 18125072@student.westernsydney. edu.au

${ }^{1}$ Centre of Health Research, School of Medicine, Western Sydney University, Building 3, Campbelltown Campus, Locked Bag 1797, Penrith, NSW 2571, Australia

Full list of author information is available at the end of the article
}

coal) for cooking and heating is a substantial cause of respiratory illness and death, due to a range health damaging pollutants such as fine particles, carbon monoxide $\left(\mathrm{CO}_{2}\right)$, nitrogen oxides $\left(\mathrm{NO}_{2}\right)$, sulphur dioxide $\left(\mathrm{SO}_{2}\right)$, benzene, butadiene, formaldehyde, polyaromatic hydro-carbons and a number of other chemicals, [4, 5] and remains a major public health concern in the developing world $[6,7]$. A recent study from India indicated that $56 \%$ of children aged under-five remained with their mother at all times during cooking [2], and that proximity to smoke from solid fuel use is associated with an increase in the risk of health problems among young children $[8,9]$.

According to World Health Organization (WHO), $3.5 \%$ of the total burden of disease in India country has been attributable to HAP [10] and a previous study from India has indicated that solid fuel use was responsible for $20 \%$ of deaths among children $<5$ years $[11,12]$. In 
addition, $24 \%$ of total deaths among children under five in India was associated with acute respiratory illness (ARIs) $[12,13]$ which has also been identified as the leading cause of death of children less than five by the 2010 Global Burden of disease (GBD) study [14]. The underfive mortality in India declined from 125 per 1,000 live births in 1990 to 74.6 per 1,000 live births in 2005-06 [15], and despite projections that it will further decline to 70 per 1,000 live births by 2015, this still does not achieve the Millennium Development Goal 4 (MDG4) target of 42 per 1,000 live births to reduce mortality among children under five by two-thirds [15].

A number of previous studies in India have reported the effects of HAP on respiratory diseases among young children [12, 16-20] and associations between HAP and under-five mortality with other health outcomes (e.g., low birth weight, respiratory illnesses among young children) [11, 21-23]. However, those studies have been limited to surveys of limited geographic areas, or hospital based data sources for specific regional populations or focused on all types of HAP (for example, including tobacco use), and not exclusively cooking fuel [24-29]. To date, no studies in India have examined changes in the association between HAP and under-five mortality over time, or investigated the role of environmental and behavioural factors that might affect the level of exposure to HAP (for example, place of residence, location of kitchen, and breastfeeding status). Accordingly, the objective of this study was to investigate trends in the association between HAP from cooking fuel and under-five mortality for three consecutive age groups (neonatal, post-neonatal and child), and to assess how this is affected by key environmental and behavioral factors using large-scale nationally representative data over the period 1992-2006.

\section{Methods}

\section{Data sources}

The data in this study were extracted from India's National Family and Health Survey (NFHS) datasets for the years 1992-93 (NFHS-1), 1998-99 (NFHS-2) and 2005-06 (NFHS-3). The NFHS are nationwide surveys based on a representative sample of households throughout the country under the authority of the Ministry of Health and Family Welfare (MOHFW), Government of India, and implemented by the International Institute for Population Sciences (IIPS), Mumbai with technical assistance from Macro International of Calverton, Maryland, USA, as a part of its Demographic and Health Surveys Program [1, 30, 31]. To date, the three NFHS surveys (NFHS-1, NFHS-2 \& NFHS-3) have collected demographic and health data by interviewing ever-married women (aged 15-49 years) and men (aged 15-54 years) using a stratified sample of households based on a twostage cluster design [1, 30, 31]. NFHS-3 covered all 29 states of India, which includes more than $99 \%$ of India's population [1].

A total of 303,361 ever-married women of reproductive age (112,357 from urban and 191,009 from rural areas) were included in the three datasets with a response rate of $95.4 \%$ in women across the three datasets (NFHS-1, NFHS-2 and NFHS-3). This study was based on information relating to 166,382 singleton live-born children, of whom 11,311 died in the 5-years prior to the survey. An index period of five years was to minimize recall bias of child birth and death information self-reported by the mother.

\section{Study outcomes}

The analysis for under-five mortality was carried out for three successive age groups: neonatal, post-neonatal and child mortality, using the following definitions:

- Neonatal mortality: The number of deaths during the first 28 days of life (0-28 days). Defined as, Number of neonatal deaths/Total number of live births

- Post-neonatal mortality: The number of deaths between one month and the first birthday (1-11 months). Defined as, Number of post-neonatal deaths/Total number of live births

- Child mortality: The number of deaths between exact ages one and five (12-59 months). Defined as, Number of child deaths/Total number of live births

The outcome variables were considered dichotomous for the analysis, where age at death was either yes $(=1)$ denoting death occurred during these any three periods of age or no $(=0)$ denoting the child survived during the age-period.

\section{Exposure to cooking fuel}

The main exposure variable was type of cooking fuel used in the household. The respondents were asked, "What type of fuel does your household mainly use for cooking?" and in response 12 types of cooking fuel were reported. In the analysis, these fuels were grouped into two categories on the basis of exposure to cooking smoke: "clean fuels" (electricity, liquid petroleum gas (LPG), natural gas and biogas) and "polluting fuels" (kerosene, coal/lignite, charcoal, wood, straw/shrubs/grass, agricultural crop waste and dung cakes). NFHS analyses have previously classified cooking fuel as "solid" and "non-solid" fuels, where kerosene was categorised in the non-exposed (i.e. "clean fuel") group [1, 30, 31]. However, some previous studies have reported kerosene as a polluting fuel and have found significant associations between underfive mortality or respiratory illness among children and 
kerosene fuel use [21, 32, 33]. For this reason, kerosene was categorised in the polluting fuels group.

\section{Potential confounders}

Place of residence (categorized as "urban" or "rural"), household wealth index (categorized as "high income", "middle income" or "low income"), mother's education (categorized as "secondary or higher", "primary" or "no education"), mother's working status (categorized as "working" or "not working") and type of house (categorized as "pucca", "semi-pucca" or "kachha") were included as markers of socio-economic status, and have previously been identified as potential confounders of the association between HAP and under-five mortality [11, 21-23, 33-38]. The household wealth index was constructed using principal components analysis, with weights for the wealth index calculated by giving scores to the asset variables such as ownership of transport, durable goods and facilities in the household [1, 30, 31, 39]. "Low income" referred to the bottom $40 \%$ of households, "middle income" referred to the middle $40 \%$ of households, and "high income" referred to the top $20 \%$ of households, based on the approach described by Filmer and Pritchett [39]. Mother's age (categorized as <20, 20-29, 30-39 and 40-49 years) and sex of the child (categorized as "female" or "male") were also considered as potential confounders of the association between HAP and under-five mortality.

Breastfeeding status of mother (categorized as ever breastfed "yes" or "no") and location of kitchen (categorized as separate room used as kitchen "yes" or "no") were also considered a priori factors that may indicate different levels of exposure to polluting fuels. No separate kitchen used for cooking in the household as an indicator of proximity to polluting fuel use has also been presented to be an significant factor associated with high exposure to HAP $[24,26-28,36,37,40]$. Additionally, breastfeeding has been shown to be a protective factor for under-five mortality, generally in neonatal and infancy period [33, 34, 41-44] which may reduce the greater risk of exposure associated with HAP. Hence, analyses sought to determine whether the magnitude of the association between HAP and under-five mortality differed by past breastfeeding status.

\section{Statistical Analysis}

The association between type of cooking fuels and under-five mortality was investigated using a series of multilevel logistic regression models adjusted for the potential confounders of household wealth, place of residence, mother's age, mother's education, mother's working status, sex of child, breastfeeding status, kitchen location and type of house. Changes in neonatal, post neonatal and child mortality incidences from HAP over time were also investigated using a trend analysis across
1992-93, 1998-99 and 2005-06 NFHS data by specifying 'period' as a continuous variable. To identify the overall effect of HAP from cooking fuels with neonatal, post-neonatal and child mortality, pooled analyses were also conducted. The extent of divergence or convergence between the slopes of period specific trends within each variable over the study period (1992-2006) was assessed by testing the interaction between period and a given confounding variable using likelihood ratio tests.

Stratified analyses were also conducted by breastfeeding status and by location of kitchen to determine whether the magnitude of the effect of the exposure on outcomes differed across levels of these variables. Breastfeeding status (ever breastfed "yes" or "no") and location of kitchen (separate room used as kitchen "yes" or "no") were each also combined with type of cooking fuel as composite ordinal variables to investigate different level of exposure to HAP for under-five mortality outcomes.

The "Svy" command was used for calculating weighted cumulative incidence estimates of mortality to adjust for the cluster sampling survey design. Random effects multilevel logistic regression models were conducted by using the "xtlogit" command and for likelihood ratio test for interaction "lrtest" command was used. Adjusted risk differences were also estimated from logistic regression model using the "margins" command. All analyses were carried out in STATA version 13.1 (Stata Corp: College Station, TX, USA).

\section{Ethics}

The Demography and Health Survey (DHS) project sought and obtained the required ethical approvals from ethics committees in India before the surveys were conducted. Informed consent was obtained from study participants before their participation in the surveys. Publicly available, de-identified datasets were used in this study following approval from The DHS Program.

\section{Results}

The overall under-five mortality incidence proportion in India decreased from 8.7 \% per year in 1992 to $6.6 \%$ per year in 2006 for those using polluting fuels for cooking. Decreasing trends were also evident for each age group, where the neonatal mortality incidence proportion declined from $4.5 \%$ in 1992 to $3.9 \%$ in 2006, post-neonatal mortality incidence proportion from $2.7 \%$ in 1992 to $1.7 \%$ in 2006 and child mortality incidence proportion from $1.5 \%$ in 1992 to $0.9 \%$ in 2006 (Fig. 1). Use of polluting fuels (kerosene, coal/lignite, charcoal, wood, straw/ shrubs/grass, agricultural crop waste and dung cakes) for cooking was associated with a higher risk of post-neonatal $(\mathrm{OR}=1.42, \quad 95 \% \mathrm{CI}=1.19-1.71, \quad P<0.001)$ and child mortality $(\mathrm{OR}=1.42, \quad 95 \% \mathrm{CI}=1.05-1.91, \quad P=0.021)$ than neonatal mortality $(\mathrm{OR}=1.23,95 \% \mathrm{CI}=1.09-1.39, P=0.001)$ 


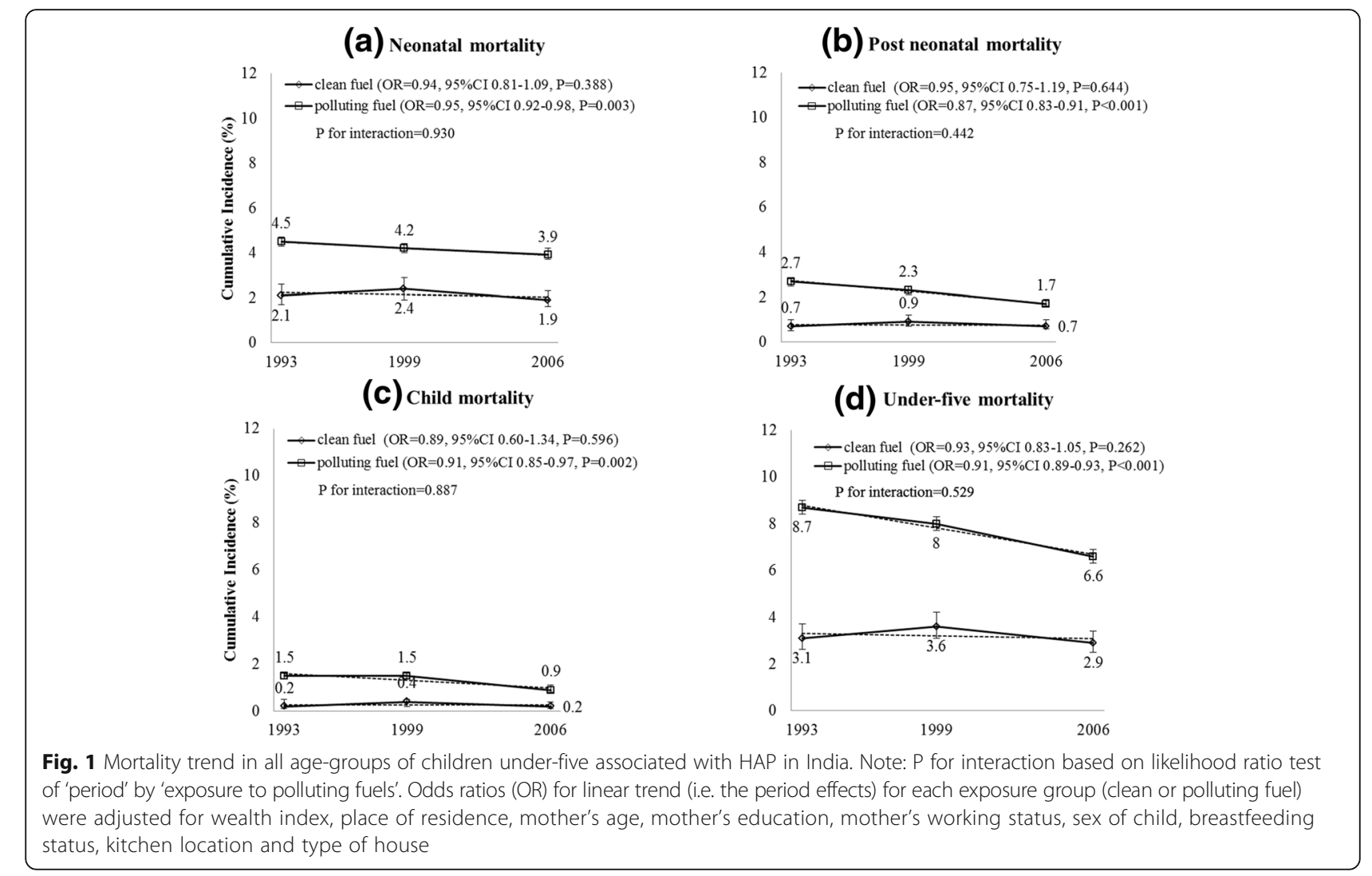

after adjusting for household wealth, place of residence, mother's age, mother's education, mother's working status, sex of child, breastfeeding status, kitchen location and type of house (Table 1). Use of polluting fuels and under-five mortality showed statistically significant association $(\mathrm{OR}=1.30,95 \% \mathrm{CI}=1.18-1.43, P<0.001)$ after adjusting for confounders (Fig. 2). Corresponding risk differences between use of clean fuel and polluting fuel were found $(0.68 \%, 95 \% \mathrm{CI}=0.33 \%-1.03 \%)$ for neonatal, $(0.61 \%, 95 \% \mathrm{CI}=0.35 \%-0.87 \%)$ for post-neonatal, $(0.34 \%, 95 \% \mathrm{CI}=0.28 \%-0.40 \%)$ for child mortality and $(1.50 \%, 95 \% \mathrm{CI}=1.01 \%-1.99 \%)$ for overall under-five mortality.

Stratified analyses to examine different levels of exposure to HAP showed more than 5-fold greater risk of mortality in women who never breastfeed and who used polluting fuels for cooking (compared to breastfeeding women who used clean fuels), with robust associations evident for child $(\mathrm{OR}=10.4795 \% \mathrm{CI}=7.13-15.37, P<$ $0.001)$ and post-neonatal $(\mathrm{OR}=8.8795 \% \mathrm{CI}=6.94-11.33$, $P<0.001)$ mortality than neonatal $(\mathrm{OR}=5.3695 \% \mathrm{CI}=$ 4.65-6.19, $P<0.001$ ) mortality (Table 2 ). In addition, the risk of under-five mortality was also higher for the women who ever breastfed but used polluting fuel for cooking (Table 2).

Analyses combining location of kitchen (separate room used as kitchen or not) and use of cooking fuels, showed strong evidence of an association between households using polluting fuels and no separate kitchen (compared to households with a separate kitchen who used clean fuel for cooking), with stronger associations for child mortality $(\mathrm{OR}=7.37,95 \% \mathrm{CI}=5.56-9.76, P<0.001)$ than post-neonatal $(\mathrm{OR}=4.03,95 \% \mathrm{CI}=3.40-4.78, P<0.001)$ and neonatal mortality $(\mathrm{OR}=2.34,95 \% \mathrm{CI}=2.11-2.59, P<$ 0.001 ) (Table 2). There was also an indication of association between use of polluting fuels in a separate kitchen and neonatal, post-neonatal and child mortality (Table 2). A sensitivity analysis was conducted including kerosene as a "clean fuel" group which did not change results substantially (only $6.94 \%$ of women reported the use of kerosene for cooking in three survey years) (data not shown).

\section{Discussion}

Under-five mortality in India has declined substantially over time, however, the association between household use of polluting fuels for cooking and under-five mortality has not changed significantly over time. The risk of death was higher in post-neonatal and child age groups than the neonatal age-group, and were generally consistent with previous studies in India and Nigeria [11, 21-23, 34]. Findings are also consistent with proposed biological mechanisms relating to key pollutants such as fine particles, carbon monoxide (CO) and a number of other chemicals present in solid cooking fuels 
Table 1 HAP associated with neonatal, post neonatal and child mortality in India: a pooled analysis for 1992-2006

\begin{tabular}{|c|c|c|c|c|c|c|c|c|c|c|c|c|}
\hline \multirow[b]{2}{*}{ Study factors } & \multicolumn{4}{|c|}{ Neonatal } & \multicolumn{4}{|c|}{ Post neonatal } & \multicolumn{4}{|l|}{ Child } \\
\hline & $\overline{n^{e}}$ & $\mathrm{n}(\%)^{f}$ & $\mathrm{OR}^{\mathrm{b}} 95 \% \mathrm{Cl}$ & $P$ value & $\mathrm{n}^{\mathrm{e}}$ & $\mathrm{n}(\%)^{f}$ & $\mathrm{OR}^{\mathrm{b}} 95 \% \mathrm{Cl}$ & $P$ value & $\overline{n^{e}}$ & $\mathrm{n}(\%)^{f}$ & $\mathrm{OR}^{\mathrm{b}} 95 \% \mathrm{Cl}$ & $P$ value \\
\hline \multicolumn{13}{|l|}{ Type of Cooking Fuel } \\
\hline Clean fuel $^{a, c}$ & 565 & 2.1 & 1.00 & & 216 & 0.8 & 1.00 & & 69 & 0.3 & 1.00 & \\
\hline Polluting fuel ${ }^{d}$ & 5517 & 4.2 & $1.23(1.09-1.39)$ & 0.001 & 3138 & 2.3 & $1.42(1.19-1.71)$ & $<0.001$ & 1806 & 1.3 & $1.42(1.05-1.91)$ & 0.021 \\
\hline \multicolumn{13}{|l|}{ Place of Residence } \\
\hline Urban $^{a}$ & 1366 & 2.9 & 1.00 & & 723 & 1.4 & 1.00 & & 307 & 0.7 & 1.00 & \\
\hline Rural & 4716 & 4.3 & $1.15(1.06-1.24)$ & 0.001 & 2631 & 2.3 & $1.05(0.94-1.16)$ & 0.383 & 1568 & 1.4 & $1.16(0.99-1.35)$ & 0.054 \\
\hline \multicolumn{13}{|l|}{ Wealth Index } \\
\hline High income $e^{a}$ & 587 & 2.2 & 1.00 & & 231 & 0.9 & 1.00 & & 76 & 0.3 & 1.00 & \\
\hline Middle income & 2111 & 3.6 & $1.27(1.13-1.42)$ & $<0.001$ & 1100 & 1.7 & $1.37(1.15-1.63)$ & $<0.001$ & 507 & 0.8 & $1.51(1.13-2.02)$ & 0.005 \\
\hline Low income & 3328 & 4.7 & $1.58(1.39-1.79)$ & $<0.001$ & 1980 & 2.6 & $1.78(1.48-2.14)$ & $<0.001$ & 1271 & 1.7 & $2.37(1.76-3.18)$ & $<0.001$ \\
\hline \multicolumn{13}{|l|}{ Mother's Age } \\
\hline $40-49^{a}$ & 187 & 4.9 & 1.00 & & 135 & 3.4 & 1.00 & & 90 & 2.3 & 1.00 & \\
\hline$<20$ & 702 & 6.4 & $2.25(1.88-2.68)$ & $<0.001$ & 308 & 2.6 & $1.37(1.11-1.71)$ & 0.004 & 75 & 0.7 & $0.43(0.32-0.60)$ & $<0.001$ \\
\hline $20-29$ & 3921 & 3.8 & $1.22(1.04-1.43)$ & 0.013 & 2144 & 2.0 & $0.98(0.81-1.18)$ & 0.814 & 1169 & 1.1 & $0.80(0.64-1.01)$ & 0.052 \\
\hline 30-39 & 1268 & 3.5 & $0.93(0.79-1.09)$ & 0.404 & 767 & 2.1 & $0.81(067-0.99)$ & 0.038 & 541 & 1.6 & $0.86(0.68-1.08)$ & 0.192 \\
\hline \multicolumn{13}{|l|}{ Mother's Education } \\
\hline Secondary/Higher ${ }^{\mathrm{a}}$ & 1301 & 2.6 & 1.00 & & 499 & 0.9 & 1.00 & & 178 & 0.3 & 1.00 & \\
\hline Primary & 944 & 3.9 & $1.28(1.16-1.41)$ & $<0.001$ & 505 & 1.9 & $1.66(1.44-1.91)$ & $<0.001$ & 199 & 0.8 & $1.56(1.25-1.94)$ & $<0.001$ \\
\hline No education & 3825 & 4.7 & $1.52(1.40-1.65)$ & $<0.001$ & 2344 & 2.7 & $2.17(1.92-2.45)$ & $<0.001$ & 1496 & 1.7 & $2.67(2.22-3.22)$ & $<0.001$ \\
\hline \multicolumn{13}{|c|}{ Mother's Working Status } \\
\hline Working ${ }^{a}$ & 2035 & 4.4 & 1.00 & & 1145 & 2.3 & 1.00 & & 769 & 1.6 & 1.00 & \\
\hline Not working & 4047 & 3.8 & $1.02(0.97-1.09)$ & 0.424 & 2209 & 2.0 & $1.05(0.97-1.13)$ & 0.233 & 1106 & 1.0 & $0.85(0.77-0.93)$ & 0.001 \\
\hline \multicolumn{13}{|l|}{ Sex of Child } \\
\hline Female $^{a}$ & 2705 & 3.7 & 1.00 & & 1721 & 2.3 & 1.00 & & 1108 & 1.5 & 1.00 & \\
\hline Male & 3377 & 4.2 & $1.17(1.10-1.23)$ & $<0.001$ & 1633 & 1.9 & $0.87(0.81-0.93)$ & $<0.001$ & 767 & 0.9 & $0.64(0.58-0.71)$ & $<0.001$ \\
\hline \multicolumn{13}{|l|}{ Breastfeeding Status } \\
\hline Ever breastfed ${ }^{a}$ & 2488 & 2.5 & 1.00 & & 1389 & 1.3 & 1.00 & & 946 & 0.9 & 1.00 & \\
\hline Never breastfed & 3594 & 7.2 & $3.64(3.44-3.86)$ & $<0.001$ & 1965 & 3.7 & $3.59(3.33-3.87)$ & $<0.001$ & 929 & 1.8 & $2.34(2.13-2.58)$ & $<0.001$ \\
\hline \multicolumn{13}{|l|}{ Separate Kitchen } \\
\hline$Y_{e s}^{a}$ & 2601 & 3.4 & 1.00 & & 1321 & 1.7 & 1.00 & & 610 & 0.8 & 1.00 & \\
\hline No & 3043 & 4.5 & $1.16(1.09-1.22)$ & $<0.001$ & 1827 & 2.6 & $1.24(1.15-1.34)$ & $<0.001$ & 1153 & 1.6 & $1.45(1.30-1.61)$ & $<0.001$ \\
\hline \multicolumn{13}{|l|}{ Type of House } \\
\hline Pucca $^{a}$ & 1104 & 3.5 & 1.00 & & 557 & 1.6 & 1.00 & & 264 & 0.8 & 1.00 & \\
\hline Semi-pucca & 1975 & 3.7 & $0.98(0.91-1.07)$ & 0.687 & 1661 & 2.0 & $1.04(0.93-1.17)$ & 0.454 & 583 & 1.1 & $0.99(0.84-1.16)$ & 0.874 \\
\hline Kachha & 2985 & 4.4 & $1.16(1.09-1.22)$ & 0.003 & 1122 & 2.4 & $1.08(0.97-1.21)$ & 0.148 & 1020 & 1.5 & $1.20(1.03-1.41)$ & 0.017 \\
\hline \multicolumn{13}{|l|}{ Year of Survey } \\
\hline $1992-1993^{\mathrm{a}}$ & 2391 & 4.3 & 1.00 & & 1438 & 2.5 & 1.00 & & 788 & 1.4 & 1.00 & \\
\hline 1998-1999 & 2104 & 4.0 & $0.95(0.89-1.02)$ & 0.137 & 742 & 2.1 & $0.88(0.81-0.95)$ & 0.002 & 731 & 1.4 & $1.08(0.97-1.20)$ & 0.161 \\
\hline $2005-2006$ & 1587 & 3.6 & $0.88(0.81-0.95)$ & 0.002 & 1174 & 1.6 & $0.74(0.67-0.82)$ & $<0.001$ & 356 & 0.8 & $0.68(0.58-0.79)$ & $<0.001$ \\
\hline
\end{tabular}

Note: ${ }^{a}$ Reference category, ${ }^{b}$ odds ratio adjusted for wealth index, place of residence, mother's age, mother's education, mother's working status, sex of child, breastfeeding status, kitchen location, type of house and year of survey, 'clean fuels: electricity, LPG, natural gas, biogas, dPolluting fuels: kerosene, coal/lignite, charcoal, wood, straw/shrubs/grass, agricultural crop and animal dung, ${ }^{e} \mathrm{n}=$ number of mortality cases of children for neonatal, post neonatal and child age-group, f percentage of mortality cases 


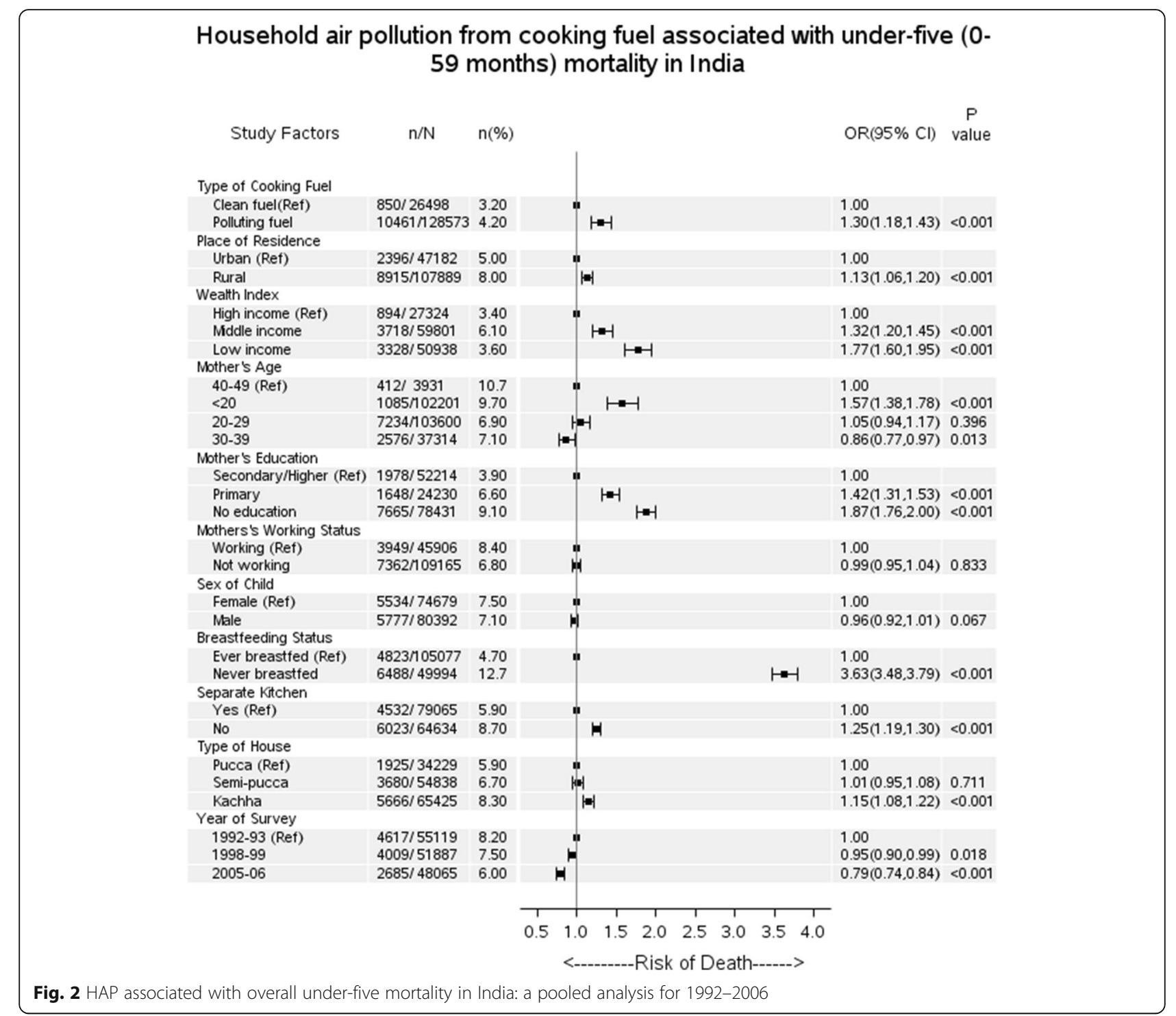

compared to clean cooking fuels. Under-five mortality in all consecutive age groups was higher in rural areas compared to urban and in households without a separate kitchen (compared to separate kitchen) for cooking their meals. There was also a lower risk of mortality in mothers who had ever breastfed compared to never breastfed which was consistent with its previously reported role in respiratory outcomes $[41,43,44]$ and which appeared to attenuate the effects of polluting fuel use, with a higher risk of under-five mortality among never breastfeeding (compared to ever breastfeeding) mothers using polluting cooking fuels.

This study found rural children were at greater risk of death than children from rural areas which was consistent with previous studies in India [11, 21, 22]. Approximately $90 \%$ of rural households in India depend on solid fuels as a domestic source of energy and the only option for cooking, whereas cleaner fuels (natural gas/LPG) were more common in urban areas [1]. Other socioeconomic factors associated factors (for example, kachha (poor) house, mother's with no education, and lower income) are also likely influences of the use of polluting fuels in rural areas.

The location of kitchen has previously been shown to be an important factor in studies of HAP and under-five mortality in developing country settings (such as, African countries and Bangladesh) [36, 37], and are also consistent with observed associations between HAP and under-five mortality in the present study which have not been shown before for India using nationally representative data sources. Analyses that incorporated the location of kitchen found a higher risk of neonatal, post-neonatal and child mortality when mothers reported no separate kitchen and used polluting fuels for cooking. Moreover, 


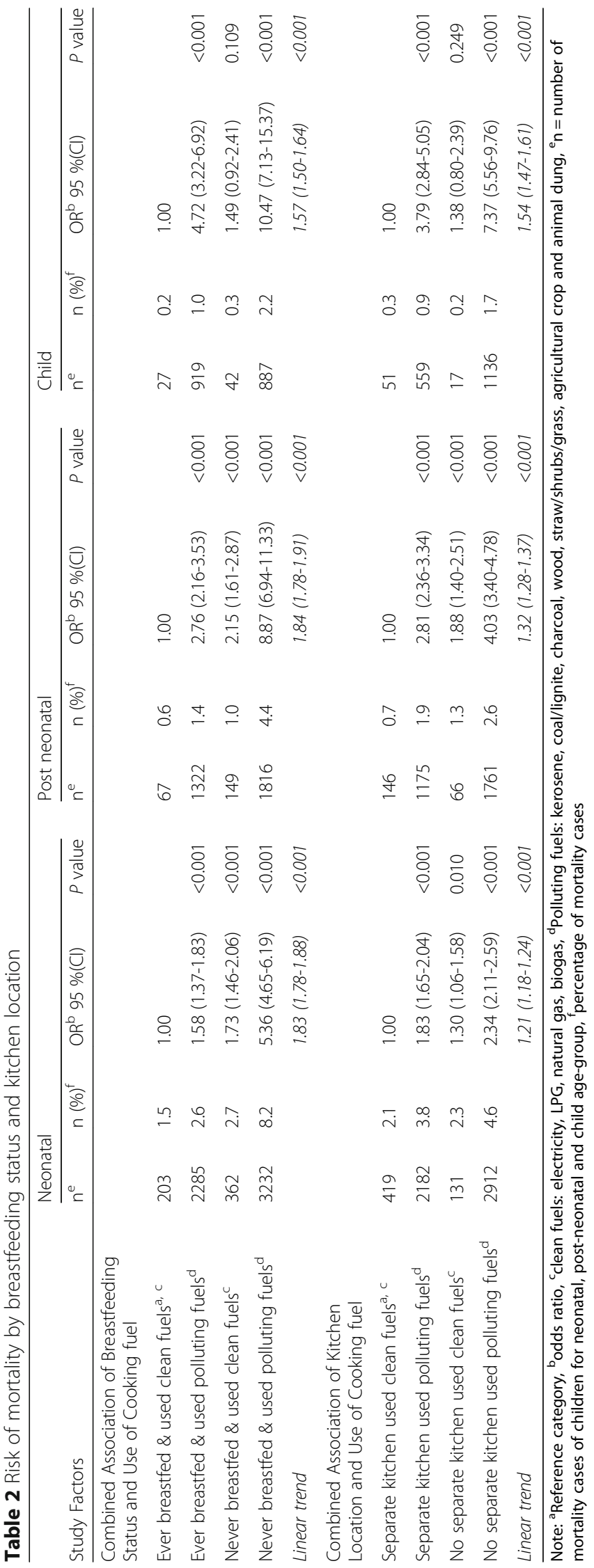


this study found that households using polluting fuels in indoor kitchen without partitions were at higher risk of death of their children under-five than household with separate kitchen both in urban and rural areas. Findings suggest that a separate kitchen in the household could reduce the death of young children even where polluting fuels were used for cooking. This is because households without a separate kitchen have higher concentrations of particles and children mainly less than five year of age were exposed to higher level of smoke as they spent many hours indoors [45].

Breastfeeding has previously been shown to protect infants against infection and has been reported as a protective factor for reducing risk of respiratory illness among infants [41, 43], and thus was a behaviour that was investigated to determine whether breastfeeding status might attenuate the association between HAP and under-five mortality. Analyses showed substantial differences in the association between HAP and under-five mortality between women who did or did not breastfeed. The strong effect of the breastfeeding status of mother was examined in the neonatal and post-neonatal period compared to older children who reported using polluting fuels, but who also breastfed their children. Therefore, breastfeeding in the first one year of life was found to be a protective factor for lower risk of mortality among young children associated with HAP, consistent with previous similar studies in Nigeria [34], but not previously shown in a South Asian context.

There are a number of methodological considerations to be taken into account when interpreting these findings. This study was based on a series of cross-sectional secondary datasets, with a number of potential sources of bias including selection, misclassification and recall bias. Firstly, the classification of cooking fuel may be a source of misclassification bias, as some households use a combination of polluting and clean fuels. Moreover, the DHS survey only collected information of primary fuel use, and there was no data for secondary fuel use. For example, one recent study on India indicated that dwellings reporting kerosene as their primary fuel frequently shift to cooking with biomass fuel (such as wood) which may cause higher concentrations of HAP $[21,46]$, and attenuate associations between HAP and under-five mortality. In addition, this study did not account for past exposure to HAP or recent changes in cooking methods because of its cross-sectional design.

Secondly, information on birth and death of children was self-reported by mothers, which may be a source of recall bias. The present study constrained analyses to those children born within a five year period prior to the survey date in order to minimise the likelihood of recall bias (and maximise the study sample size). Thirdly, this study used cross-sectional data for analysis, and it is difficult to clearly define temporal relationships between the exposure and outcome when collected at the same point of time.

Furthermore, we considered all-cause mortality for our analysis of the association between HAP and under-five mortality. Cause of death information was not available in the NFHS dataset used for this study. Verbal autopsy questionnaires are employed for identifying cause of death in developing countries, including India; however this information is often of variable quality and was not collected for India NFHS data. Not only pneumonia and acute respiratory infections but also other factors, such as preterm birth complications, low birth weight, nutritional conditions and diarrhoea also affect mortality among under-five children but we could not measure cause-specific death due to lack of data. The 2010 GBD study indicated that acute lower respiratory infections was the second leading cause of death (after preterm birth complications) in under-five children in India [14]. HAP from cooking fuel is a primary cause for respiratory infections among underfive children and thus can be associated with the deaths caused by those illnesses. However, including all-cause mortality will also include mortality outcomes not associated with HAP, which is likely to be a source of ascertainment bias in the outcome, and lead to an underestimation of the association between HAP and the cause-specific outcomes noted above.

This study also did not measure actual levels and patterns of exposure to emission from cooking smoke due to the absence of such information in DHS data. Proxy environmental and behavioural measures were defined to examine the effects of level of exposure. Location of kitchen was used as a proxy measure to investigate the effects of different level of exposure associated with HAP and under-five mortality and several studies in India noted a significant association between HAP and kitchen location [18, 45, 47, 48]. Other proxy measures such as 'presence of window', and 'cooking under a chimney' were available at NFHS-3; however this information were not collected in previous surveys.

Despite these methodological concerns, this present study used large-scale nationally representative DHS data with a very high response rate of $95.4 \%$, and was the first study to pool datasets over a long period (1992-2006), a period in India characterised by rapid socio-economic development. No previous studies have investigated trends and differentials in the association between HAP and under-five mortality in India over this long period, or assessed the role of environmental and behavioural factors that may be points of intervention and health promotion at the national level in the Indian context to further contribute to declines in under-five mortality in the post-MDG period.

The magnitude of the association between HAP and under-five mortality remained consistent over time in all 
age-groups and higher exposure to cooking fuel can substantially increase the risk of respiratory illness and child deaths in developing countries like India. According to NFHS-3, only $0.4 \%$ of the households had access to electricity and $24.7 \%$ of households used LPG/natural gas, with the remainder still relying on polluting fuels in both urban and rural areas [1]. Despite the potentially small relative risk of under-five mortality associated with HAP, it remains a common exposure in the population and therefore the population attributable risk - of this preventable risk factor - remains a public health priority for India.

Raising awareness about the health risk related with HAP and the use of polluting fuel is needed in rural and low income urban areas. Radio and television have been identified as useful media to raise awareness and to reach poorer sub-groups of the population $[49,50]$. The most important intervention to reduce exposure to polluting fuel is ready access to clean fuels such as LPG/natural gas, biogas and electricity [18, 19, 22]. Many countries like Brazil, Bolivia, Ecuador have decreased exposure to pollution from cooking fuel by promoting liquid fuel supported by government policy [22, 51]. Switching to clean fuel is advisable, however, it is not an affordable option for many poor families in India and supplying cleaner fuel to rural household is expensive, and thus requires long term intervention because of poor infrastructure in India $[18,19,22]$.

Behavioral change interventions also have potential, and are shorter term alternatives in India to reduce child exposure from HAP $[18,19,22]$. Studies from India suggested that improvements in natural household ventilation, particularly windows and improved stoves (stoves with chimney) might lead to a reduction in $\operatorname{HAP}[18,19,22]$. Cooking stoves with a chimney also have health advantages, via reductions in carbon monoxide emissions and incidence of respiratory infections [52, 53]. Studies showed that India has distributed ten millions of improved cooking stoves since 1980 and plans to distribute 150 million in the next decade [54, 55]. Findings from this study suggests that, behavioral interventions are likely to play a key role in decreasing childhood deaths in India by promoting the use of improved cooking stoves, raising awareness for cooking in a separate kitchen and removing children from the cooking area while cooking, increasing natural ventilation in household and implementing concerted health promotion campaigns to inform people about public health hazard relating to HAP.

\section{Conclusions}

The overall under-five mortality rates in India have decreased substantially over the study period (1992-2006). While HAP was associated with a modest increase in risk of mortality in children under five, the ubiquitous use of polluting fuel in India and associated population attributable risk, confirms that HAP remains an important public health problem. Cooking fuel is a modifiable risk factor that can be changed by improvements in house design, health system policies, infrastructure, behavioural intervention and economic development of the country.

\section{Abbreviations \\ HAP: Household Air Pollution; NFHS: National Family and Health Survey; WHO: World Health Organization; ARI: Acute Respiratory Infection; GBD: Global Burden of Disease; MDG: Millennium Development Goal; MOHFW: Ministry of Health and Family Welfare; IIPS: International Institute for Population Sciences; LPG: Liquid Petroleum Gas; DHS: Demography and Health Survey.}

\section{Competing interests}

The authors declare that they have no competing interests.

\section{Authors' contributions}

SN and AP contributed to the conception and design of this study. SN performed the literature review and analysis and drafted the manuscript. AP and KEA contributed to the interpretation, and critical revisions of the manuscript. All authors read and approved the final manuscript.

\section{Acknowledgements}

This study was part of the first author's thesis for a doctoral dissertation with the School of Medicine at the Western Sydney University, Australia. We are grateful to The DHS Program, ORC Macro, Calverton, Maryland, USA for providing the Indian DHS data sets for this analysis.

\section{Author details}

${ }^{1}$ Centre of Health Research, School of Medicine, Western Sydney University, Building 3, Campbelltown Campus, Locked Bag 1797, Penrith, NSW 2571 Australia. ${ }^{2}$ School of Science and Health, Western Sydney University, Campbelltown Campus, Locked Bag 1797, Penrith, NSW 2571, Australia.

Received: 17 December 2015 Accepted: 19 April 2016

Published online: 26 April 2016

\section{References}

1. International Institute for Population Science and Macro International. National Family Health Survey (NFHS-3), 2005-06: India: Volume I. Mumbai: IIPS. 2007. https://dhsprogram.com/pubs/pdf/FRIND3/FRIND3-Vol1AndVol2. pdf. Accessed 16 Dec 2015.

2. Chakraborty D, Mondal NK, Datta JK. Indoor pollution from solid biomass fuel and rural health damage: A micro-environmental study in rural area of Burdwan, West Bengal. International Journal of Sustainable Built Environment. 2014:3(2):262-71

3. Sinha SN, Kulkarni P, Shah S, Desai N, Patel G, Mansuri M, Saiyed $H$. Environmental monitoring of benzene and toluene produced in indoor air due to combustion of solid biomass fuels. Sci Total Environ. 2006:357(1):280-7.

4. Naeher LP, Brauer M, Lipsett M, Zelikoff JT, Simpson CD, Koenig JQ, Smith KR. Woodsmoke health effects: a review. Inhal Toxicol. 2007;19(1):67-106.

5. WHO: Air quality guidelines for particulate matter, ozone, nitrogen dioxide and sulfur dioxide: global update 2005: summary of risk assessment. http://apps.who.int/iris/bitstream/10665/69477/1/WHO_ SDE_PHE_OEH_06.02_eng.pdf. Accessed 16 Dec 2015.

6. Fullerton DG, Bruce N, Gordon SB. Indoor air pollution from biomass fuel smoke is a major health concern in the developing world. Trans R Soc Trop Med Hyg. 2008;102(9):843-51.

7. Smith KR, Mehta S. The burden of disease from indoor air pollution in developing countries: comparison of estimates. Int J Hyg Environ Health. 2003;206(4-5):279-89.

8. Martin II WJ, Hollingsworth JW, Ramanathan V. Household air pollution from cookstoves: impacts on health and climate. In: Global Climate Change and Public Health. Springer; 2014. p. 237-55. 
9. Rehfuess E, Bruce N, Smith K. Solid Fuel Use: Health Effect. In: Nriagu JO (ed.) Encyclopedia of Environmental Health, v 5, pp. 150161 Burlington: Elsevier, 2011. Environmental Health 2011;5:150161.

10. WHO: Indoor air pollution: national burden of disease estimates. http:// www.who.int/indoorair/publications/indoor_air_national_burden_estimate_ revised.pdf. Accessed 16 Dec 2015.

11. Bassani DG, Jha P, Dhingra N, Kumar R. Child mortality from solid-fuel use in India: a nationally-representative case-control study. BMC Public Health. 2010;10(1):491

12. Upadhyay AK, Singh A, Kumar K, Singh A. Impact of indoor air pollution from the use of solid fuels on the incidence of life threatening respiratory illnesses in children in India. BMC Public Health. 2015;15(1):300.

13. WHO: Causes of child mortality, by country, 2000-2010. http://www.who.int/ gho/child_health/mortality/mortality_causes_text/en/.Accessed 16 Dec 2015.

14. Institute for Health Metrics and Evaluation (IHME) : GBD PROFILE: India. http://www.healthdata.org/sites/default/files/files/country_profiles/GBD/ inme gbd country report india.pdf. Accessed 16 Dec 2015.

15. Patel I, Chang J, Srivastava J, Balkrishnan R. India's Progress towards the health related Millennium Development Goals-Child Mortality. Indian Jornal of Pharmacy Practice 2011;4(4).

16. Broor S, Pandey RM, Ghosh M, Maitreyi RS, Lodha R, Singhal T, Kabra SK. Risk factors for severe acute lower respiratory tract infection in under-five children. Indian Pediatr. 2001;38(12):1361-9.

17. Mahalanabis D, Gupta S, Paul D, Gupta A, Lahiri M, Khaled M. Risk factors for pneumonia in infants and young children and the role of solid fuel for cooking: a case-control study. Epidemiol Infect. 2002;129(01):65-71.

18. Mishra V, Smith KR, Retherford RD. Effects of cooking smoke and environmental tobacco smoke on acute respiratory infections in young Indian children. Popul Environ. 2005;26(5):375-96.

19. Ramesh Bhat $Y$, Manjunath N, Sanjay D, Dhanya Y. Association of indoor air pollution with acute lower respiratory tract infections in children under 5 years of age. Paediatr Int Child Health. 2012;32(3):132-5.

20. Sharma S, Sethi GR, Rohtagi A, Chaudhary A, Shankar R, Bapna JS, Joshi V, Sapir DG. Indoor air quality and acute lower respiratory infection in Indian urban slums. Environ Health Perspect. 1998;106(5):291.

21. Epstein MB, Bates MN, Arora NK, Balakrishnan K, Jack DW, Smith KR. Household fuels, low birth weight, and neonatal death in India: the separate impacts of biomass, kerosene, and coal. Int J Hyg Environ Health. 2013;216(5):523-32.

22. Pandey S, Lin Y. Adjusted effects of domestic violence, tobacco use, and indoor Air pollution from use of solid fuel on child mortality. Matern Child Health J. 2013;17(8):1499-507.

23. Tielsch JM, Katz J, Thulasiraj RD, Coles CL, Sheeladevi S, Yanik EL, Rahmathullah $\mathrm{L}$. Exposure to indoor biomass fuel and tobacco smoke and risk of adverse reproductive outcomes, mortality, respiratory morbidity and growth among newborn infants in south India. Int J Epidemiol. 2009;38(5):1351-63.

24. Gurley E, Homaira N, Salje H, Ram P, Haque R, Petri W, Bresee J, Moss W, Breysse $P$, Luby S. Indoor exposure to particulate matter and the incidence of acute lower respiratory infections among children: A birth cohort study in urban Bangladesh. Indoor Air. 2013;23(5):379-86

25. Gurley ES, Salje H, Homaira N, Ram PK, Haque R, Petri Jr WA, Bresee J, Moss WJ, Luby SP, Breysse P, et al. Seasonal concentrations and determinants of indoor particulate matter in a low-income community in Dhaka, Bangladesh. Environ Res. 2013;121:11-6.

26. Khalequzzaman M, Kamijima M, Sakai K, Chowdhury NA, Hamajima N, Nakajima T. Indoor air pollution and its impact on children under five years old in Bangladesh. Indoor Air. 2007;17(4):297-304.

27. Khalequzzaman M, Kamijima M, Sakai K, Ebara T, Hoque BA, Nakajima T. Indoor air pollution and health of children in biomass fuel-using households of Bangladesh: comparison between urban and rural areas. Environ Health Prev Med. 2011;16(6):375-83.

28. Khalequzzaman M, Kamijima M, Sakai K, Hoque BA, Nakajima T. Indoor air pollution and the health of children in biomass-and fossil-fuel users of Bangladesh: situation in two different seasons. Environ Health Prev Med. 2010;15(4):236-43.

29. Murray E, Brondi L, Kleinbaum D, McGowan J, Van Mels C, Brooks W Goswami D, Ryan P, Klein M, Bridges C. Cooking fuel type, household ventilation, and the risk of acute lower respiratory illness in urban Bangladeshi children: a longitudinal study. Indoor Air. 2012;22(2):132-9.

30. International Institute for Population Science (IIPS). National Family Health Survey (MCH and Family Planing), India 1992-93. Mumbai: IIPS.
1995. http://www.dhsprogram.com/pubs/pdf/FRIND1/FRIND1.pdf. Accessed 16 Dec 2015. Accessed 16 Dec 2015.

31. International Institute for Population Science (IIPS) and ORC Macro. National Family Health Survey (NFHS-2), 1998-99: India. Mumbai: IIPS. 2000. http://www.dhsprogram.com/pubs/pdf/FRIND2/FRIND2.pdf. Accessed 16 Dec 2015.

32. Choi J-Y, Baumgartner J, Harnden S, Alexander BH, Town RJ, D'Souza G, Ramachandran $\mathrm{G}$. Increased risk of respiratory illness associated with kerosene fuel use among women and children in urban Bangalore, India. Occup Environ Med. 2015;72(2):114-22.

33. Wichmann J, Voyi K. Influence of cooking and heating fuel use on 1-59 month old mortality in South Africa. Matern Child Health J. 2006;10(6):553-61.

34. Ezeh OK, Agho KE, Dibley MJ, Hall JJ, Page AN. The effect of solid fuel use on childhood mortality in Nigeria: evidence from the 2013 cross-sectional household survey. Environ Health. 2014;13(1):113.

35. Kashima S, Yorifuji T, Tsuda T, Ibrahim J, Doi H. Effects of traffic-related outdoor air pollution on respiratory illness and mortality in children, taking into account indoor air pollution, in Indonesia. J Occup Environ Med. 2010:52(3):340-5.

36. Naz S, Page A, Agho KE. Household Air Pollution and Under-Five Mortality in Bangladesh (2004-2011). Int J Environ Res Public Health. 2015:12(10):12847-62.

37. Rehfuess EA, Tzala L, Best N, Briggs DJ, Joffe M. Solid fuel use and cooking practices as a major risk factor for ALRI mortality among African children. J Epidemiol Community Health. 2009;63(11):887-92.

38. Rinne ST, Rodas EJ, Rinne ML, Simpson JM, Glickman LT. Use of biomass fuel is associated with infant mortality and child health in trend analysis. Am J Trop Med Hyg. 2007;76(3):585-91.

39. Filmer $D$, Pritchett LH. Estimating wealth effects without expenditure data-or tears: an application to educational enrollments in states of India. Demography. 2001;38(1):115-32.

40. Dasgupta S, Huq M, Khaliquzzaman M, Pandey K, Wheeler D. Indoor air quality for poor families: new evidence from Bangladesh. Indoor Air. 2006;16(6):426-44.

41. Arifeen S, Black RE, Antelman G, Baqui A, Caulfield L, Becker S. Exclusive breastfeeding reduces acute respiratory infection and diarrhea deaths among infants in Dhaka slums. Pediatrics. 2001;108(4):e67-e67.

42. Black RESSJ. Where and why are 10 million children dying every year? Lancet. 2003;361(9376):2226.

43. Cushing AH, Samet JM, Lambert WE, Skipper BJ, Hunt WC, Young SA, McLaren LC. Breastfeeding reduces risk of respiratory illness in infants. Am J Epidemiol. 1998;147(9):863-70.

44. Heinig MJ. Host defense benefits of breastfeeding for the infant: effect of breastfeeding duration and exclusivity. Pediatr Clin North Am. 2001;48(1):105-23.

45. Prasad R, Singh A, Garg R, Hosmane GB. Biomass fuel exposure and respiratory diseases in India. Drug Discoveries \& Therapeutics 2012, 6(5):219-28.

46. Balakrishnan K, Ramaswamy P, Sambandam S, Thangavel G, Ghosh S, Johnson $\mathrm{P}$, et al. Air pollution from household solid fuel combustion in India: an overview of exposure and health related information to inform health research priorities. Glob Health Action. 2011;4

47. Agrawal S. Effect of indoor air pollution from biomass and solid fue combustion on prevalence of self-reported asthma among adult men and women in India: findings from a nationwide large-scale cross-sectional survey. J Asthma. 2012;49(4):355-65.

48. Mishra VK, Retherford RD. Cooking smoke increases the risk of acute respiratory infection in children. 1997. http://www.eastwestcenter.org/ fileadmin/stored/pdfs/NFHSbull008.pdf. Accessed 16 Dec 2015.

49. Ahmed LA. Women's roles in addressing indoor air pollution issues in Bangladesh: Knowledge and attitude. Providence, RI, United States: Brown University; 2003.

50. Rouse J. Indoor air pollution: issues for Bangladesh. UK-Water, Engineering and Development Centre (WEDC): Loughborough University; 2000. Accessed 16 Dec 2015.

51. Polsky D, Ly C. The health consequences of indoor air pollution: A review of the solutions and challenges. White paper Philadelphia: University of Pennsylvania Retrieved October 2012, 8:2012.

52. Chengappa C, Edwards R, Bajpai R, Shields KN, Smith KR. Impact of improved cookstoves on indoor air quality in the Bundelkhand region in India. Energy Sustain Dev. 2007;11(2):33-44.

53. Roden CA, Bond TC, Conway S, Pinel ABO, MacCarty N, Still D. Laboratory and field investigations of particulate and carbon monoxide emissions from traditional and improved cookstoves. Atmos Environ. 2009;43(6):1170-81. 
54. Kishore V, Ramana P. Improved cookstoves in rural India: how improved are they?: A critique of the perceived benefits from the National Programme on Improved Chulhas (NPIC). Energy. 2002;27(1):47-63.

55. Wilkinson $P$, Smith KR, Davies $M$, Adair $H$, Armstrong BG, Barrett M, Bruce N, Haines A, Hamilton I, Oreszczyn T. Public health benefits of strategies to reduce greenhouse-gas emissions: household energy. Lancet. 2009;374(9705):1917-29.

Submit your next manuscript to BioMed Central and we will help you at every step:

- We accept pre-submission inquiries

- Our selector tool helps you to find the most relevant journal

- We provide round the clock customer support

- Convenient online submission

- Thorough peer review

- Inclusion in PubMed and all major indexing services

- Maximum visibility for your research

Submit your manuscript at www.biomedcentral.com/submit 